\title{
Urban mining: hibernating copper stocks in local power grids
}

Joakim Krook, Mats Eklund, Per Frändegård, Niclas Svensson and Annica Carlsson

\section{Linköping University Post Print}

N.B.: When citing this work, cite the original article.

Original Publication:

Joakim Krook, Mats Eklund, Per Frändegård, Niclas Svensson and Annica Carlsson, Urban mining: hibernating copper stocks in local power grids, 2011, Journal of Cleaner Production, (19), 9-10, 1052-1056.

http://dx.doi.org/10.1016/j.jclepro.2011.01.015

Copyright: Elsevier Science B.V., Amsterdam.

http://www.elsevier.com/

Postprint available at: Linköping University Electronic Press

http://urn.kb.se/resolve?urn=urn:nbn:se:liu:diva-67254 


\title{
Urban Mining: hibernating copper stocks in local power grids
}

\author{
Joakim Krook $^{\mathrm{a},{ }^{*}, \text { Annica Carlsson }}{ }^{\mathrm{b}}$, Mats Eklund ${ }^{\mathrm{a}}$, Per Frändegård ${ }^{\mathrm{a}}$, Niclas Svensson ${ }^{\mathrm{a}}$ \\ ${ }^{a}$ Department of Management and Engineering, Environmental Technology and Management, Linköping \\ University, SE-581 83 Linköping, Sweden \\ ${ }^{b}$ The Environmental Accounts, Statistics Sweden, Box 24300, SE-104 51 Stockholm, Sweden and \\ Environmental Strategies Research - fms, Royal Institute of Technology, SE-100 44 Stockholm, Sweden \\ * Corresponding author, joakim.krook@liu.se, +46 13 288903, fax +4613149403
}

Keywords: Resource recovery, cables, metal stocks, hibernation, economic performance

\begin{abstract}
Large technical systems serving the everyday needs of people, such as water supply systems, power grids or communication networks, are rich in accumulated metals. Over time, parts of these systems have been taken out of use without the system infrastructure being removed from its original location. Such metal stocks in hibernation thus constitute potential resource reservoirs accessible for recovery. In this paper, obsolete stocks of copper situated in the local power grids of two Swedish cities are quantified. Emphasis is also on economic conditions for extracting such "hibernating" cables. The results show that on a per customer basis, the two power grids contain similar amounts of copper, i.e. 0.04-0.05 tonnes per subscriber. However, the share of the copper stock that is in hibernation differs between the grids. In the larger grid of Gothenburg, almost $20 \%$ of the copper accumulated in the grid is no longer in use, while the obsolete share does not exceed $5 \%$ in the city of Linköping. For managers of local power grids, recovery of hibernating cables could be beneficial if integrated with other maintenance work on the grid. At the present price of copper, however, separate recovery of obsolete cables is not economically justified.
\end{abstract}




\section{Introduction}

Metal flows related to human activities have been studied for decades within the research field of industrial ecology, often in order to identify sources of environmental pollution (Anderberg and Stigliani, 1994; Bergbäck et al., 2001; Lindqvist and von Malmborg, 2004; Van der Voet et al., 2000). In recent years, however, there has also been an increased interest in analysing stocks of metals in actual use in society, their spatial distribution and discard rates as a function of time (e.g. Kapur, 2006; Recalde et al., 2008; van Beers and Graedel, 2003; Wittmer and Lichtensteiger, 2007). This emerging research is largely driven by resource availability concerns, exploring the potential of using new, alternative sources for metal extraction in the future. Such an approach, where stocks of materials situated in the urban environment are seen as resource reservoirs for collection and recovery, is often termed "urban mining" (Brunner and Rechberger, 2004).

Research related to urban mining has so far primarily dealt with the potential of long-term strategies for managing such urban ores through successively increasing recycling rates of annual discards. This is because a large share of the metals accumulated in a society are often still in use and therefore not yet available for recovery (cf. Gordon et al., 2006, Kapur and Graedel, 2006; Lifset et al., 2002; Müller et al., 2006). Large technical systems supporting the everyday needs of society such as telecommunication, power and water supply systems have generally been constructed and maintained in order to remain in service for long periods of time (Gerst and Graedel, 2008; UNEP, 2010). These systems are often are rich in the metals iron, zinc, copper and aluminium.

Almost a decade ago, it was recognised that metal stocks in buildings, infrastructure and other durable goods have, over time, been taken out of use without being collected for waste management (Bergbäck et al., 2001; Hedbrant, 2003). Such accumulations of obsolete materials, that even now could be accessible for recovery, were formerly referred to as hibernating stocks. Possible locations where such metals in hibernation can be found are old water supply and sewage networks, gas, power and telecommunication grids or decommissioned military and industrial structures. Another perhaps more everyday example of this phenomenon are the out-ofdate electronic gadgets and other products stored in an attic or closet in people's dwellings or elsewhere in the urban environment (Kapur and Graedel, 2006; Müller et al., 2006). It would be fair to say however that there is still a general lack of knowledge regarding the actual occurrence and magnitude of such hibernating materials. Even more lacking is information regarding technical, economic and institutional conditions for realising the promising but so far largely theoretical approach of urban mining.

This study aims to take a first step in going beyond the sole accounting of total metal stocks situated in the urban environment and analysing the share of such accumulations that are in 
hibernation. In doing so, we specifically analyse stocks of copper in the power grids of two Swedish cities. An equally important contribution of this study involves assessing economic conditions for extracting obsolete power cables located in the city environment.

\section{Method}

The analytical approach applied in this study can be divided into three parts. First, the power grids in the cities of Gothenburg and Linköping were characterised regarding their total cable length, voltage levels, locations and operational status. In-use and hibernating stocks of copper situated in these local power networks were then quantified by multiplying the cable length with an average copper concentration. Finally, the conditions for recovery of cables in hibernation were assessed with an emphasis on economic aspects.

\subsection{Characterisation of the power grids in Gothenburg and Linköping}

In Sweden, the cable grid for distribution of electricity is comparable to a road network, including highways, national and local roads. The highways are the national power grid that is owned by the Swedish state. A handful of companies then split on the regional grids, whose main function is to transport electricity from the national grid to the local networks situated in cities. These local grids involve hundreds of operators distributing power to the final consumers. This paper incorporates two case studies on the power grids in Gothenburg and Linköping for the year 2008. In Gothenburg, 251,000 subscribers are served by the grid consisting of almost 7,000 km of medium- and low-voltage power cables primarily buried in soil, Table 1 . The length of the cable network in Linköping is about half that in Gothenburg; however, this area is less densely populated and the grid therefore only serves around 90,000 subscribers. In both cities, the grids are owned and operated by one single actor.

Table 1. Total length (in $\mathrm{km}$ ) of the power grids in Gothenburg and Linköping divided by medium- and low-voltage levels. The distribution between airborne power cables and cables buried in soil is also presented, data for 2008 (Swedish Market Inspectorate, 2010).

\begin{tabular}{lcccc}
\hline & \multicolumn{2}{c}{ Gothenburg } & \multicolumn{2}{c}{ Linköping } \\
Type of cable & Airborne cables & Cables in soil & Airborne cables & Cables in soil \\
\hline Medium-voltage $(6-24 \mathrm{kV})$ & 161 & 2106 & 307 & 653 \\
Low-voltage $(0.4 \mathrm{kV})$ & 310 & 4305 & 88 & 2112 \\
Total length & \multicolumn{2}{c}{$6882 \mathrm{~km}$} & \multicolumn{3}{c}{$3160 \mathrm{~km}$} \\
\hline
\end{tabular}

Both in Gothenburg and Linköping, the owners of the power grids have kept a continuous record of their networks. Taking Linköping as an example, the documentation started along with the early expansion of the power grid, at the beginning of the twentieth century, with hand-written records on map segments. Later on such information about the magnitude, composition, spatial distribution and operational status of the grid was recorded on 1:400 city planning maps. Since 
around 2000, however, all technical data about the city power cables is kept within Geographical Information Systems (GIS).

Simply put, GIS can be described as a combination of maps and tables of information stored and handled on data servers. The map data is encoded and stored in the form of geographic coordinates, while the related table data can be stored and handled by conventional methods such as spread sheet or database programmes. Within the GIS, each power cable is encoded as a separate object with attribute data such as the location, type of cable, length and operational status, i.e. in-use or disconnected. All objects belonging to a certain group of cables such as disconnected low-voltage cables also have the same classification code, which makes it possible to extract comprehensive maps and data tables for selected parts of the grid, Figure 1. Such GIS data was reviewed in order to quantify the amount of different power cables that over time have been disconnected without being recovered in the two cities. In the case of Gothenburg, almost $20 \%$ of the medium-voltage cables $(521 \mathrm{~km})$ and $13 \%$ of the low-voltage cables $(692 \mathrm{~km})$ were found to be no longer in use. For Linköping, only about $5 \%$ of the medium-voltage cables (46 $\mathrm{km})$ and $3 \%$ of the low-voltage cables $(63 \mathrm{~km})$ were in hibernation.

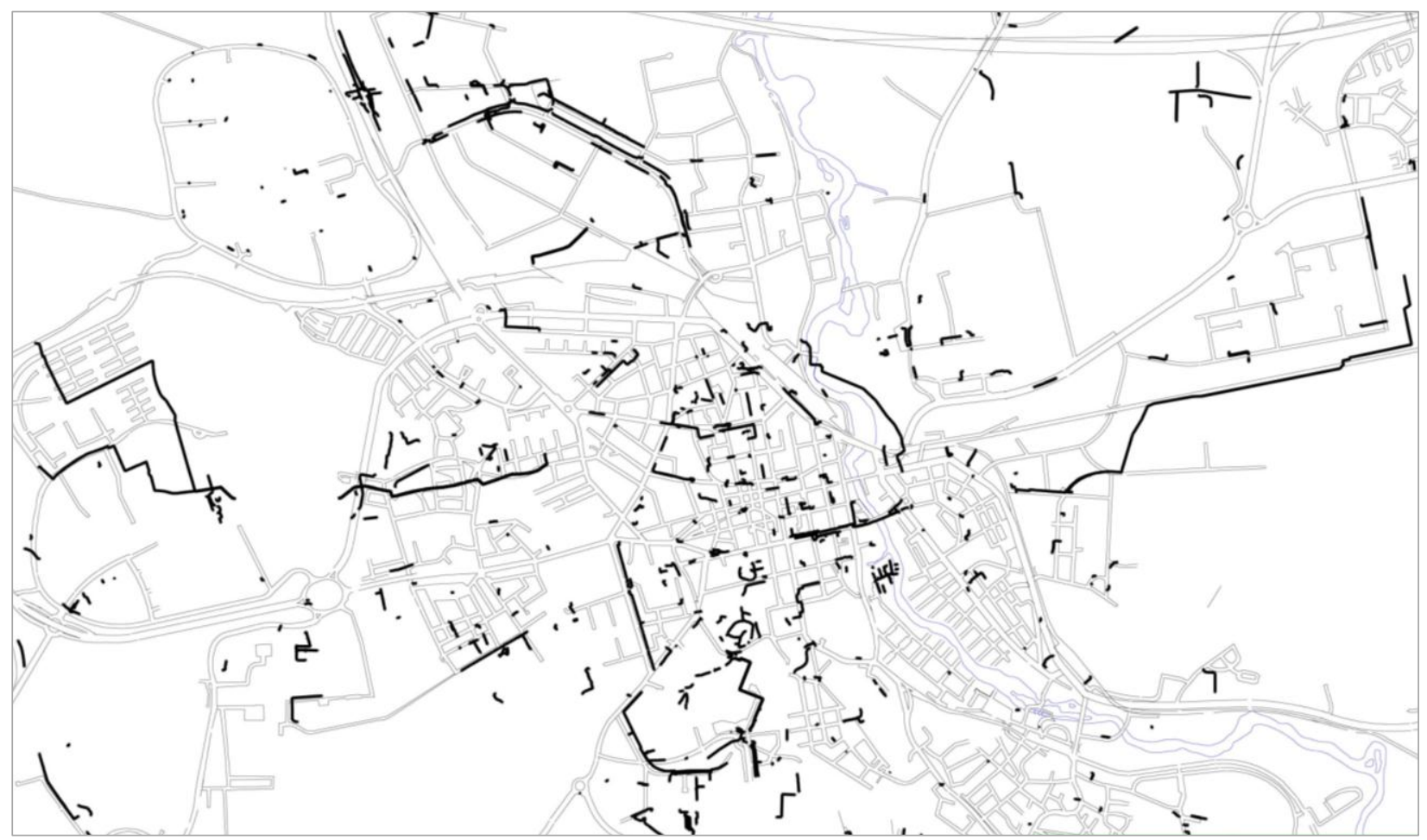

Figure 1. Map of disconnected low- and medium-voltage power cables (bold black lines) in the city center of Linköping retrieved from the power grid manager's GIS-data. The scale of the map is 1:20000. 


\subsection{Stocks of copper in power cables in-use and in hibernation}

Medium- and low-voltage power grids consist either of cables with copper as the main conductor or aluminium conductors in which copper is only used as a cable shield. Since these conductors contain significantly different amounts of copper, their relative share in the studied grids had to be considered when calculating stocks of copper, Table 2. In addition, low-voltage grids comprise both feeder and service cables, of which the latter generally are much less rich in copper (Wendell, 2005). Typical contents of copper in different types of cables were retrieved from SwedEnergy (2009) in order to calculate average concentrations for medium- and lowvoltage cables. By multiplying these concentrations of copper with the cable length of the two studied grids, the total stocks of copper in-use and in hibernation were assessed.

Table 2. Share of medium- and low-voltage cables consisting of copper conductors and aluminium conductors and their typical copper content, rounded numbers. The calculated average copper content of medium- and low-voltage cables situated in the power grids of Gothenburg and Linköping is also presented.

\begin{tabular}{|c|c|c|c|c|c|}
\hline & \multicolumn{2}{|c|}{ Copper conductor } & \multicolumn{2}{|c|}{ Aluminium conductor } & \multirow{2}{*}{$\begin{array}{c}\text { Calculated } \\
\text { average copper } \\
\text { content } \\
\mathrm{kg} \mathrm{Cu} / \mathrm{m}\end{array}$} \\
\hline & $\mathrm{kgCu} / \mathrm{m}^{a}$ & Share in grids ${ }^{b}$ & $\mathrm{kgCu} / \mathrm{m}^{a}$ & Share in grids ${ }^{b}$ & \\
\hline Medium voltage $(6-24 \mathrm{kV})$ & 3.3 & 0.5 & 0.1 & 0.5 & $1.7^{\mathrm{c}}$ \\
\hline Low voltage, feeder $(0,4 \mathrm{kV})$ & 3.3 & 0.5 & 0.4 & 0.5 & $12^{\mathrm{c}}$ \\
\hline Low voltage, service $(0,4 \mathrm{kV})$ & 0.8 & 0.8 & 0.3 & 0.2 & 1.2 \\
\hline
\end{tabular}

${ }^{a}$ Typical concentrations of copper in different medium-voltage cables retrieved from SwedEnergy (2009)

${ }^{\mathrm{b}}$ Based on Wendell (2005)

${ }^{c}$ The average copper content per metre of medium- and low-voltage cables in the studied grids was calculated as follows: (share of copper conductors in the grid*kg Cu/m)+(share of aluminium conductors in the grid*kg Cu/m). For low-voltage cables it was also assumed that $45 \%$ and $55 \%$ consist of feeder and service cables respectively (Wendell, 2005).

\subsection{Analysis of conditions for cable recovery in the city of Linköping}

The manager of the power grid in Linköping was interviewed. This semi-structured interview aimed to provide knowledge about how such a large technical system is operated and maintained in practice. Emphasis was on identifying reasons for why cables end up in hibernation in the first place and the potential of recovering such obsolete products. Different technical and institutional challenges for extracting hibernating power cables were discussed with the manager during this interview.

In order to make recovery of hibernating cables an economic option for managers of power grids, the revenues for cables must simply outweigh the costs of extraction. In this study, the economic performance of cable recovery in the city of Linköping was assessed assuming two different approaches: separate recovery of hibernating cables and integrated recovery during other maintenance work. Separate cable recovery incurs many different project costs, all of which have to be allocated to the extraction of the hibernating cables. In this paper, we have included costs 
for excavation and site restoration (including asphalting), temporary storage of excavated soil, land rental from the municipality, shutting off traffic and handling of extracted cables (SwedEnergy, 2009). A typical level for each of these different costs was developed together with the manager of the power grid in Linköping. If extracting hibernating cables is done along with other maintenance work on the grid, however, most of these costs cannot be allocated to the recovery cables, as these expenditures would have occurred anyway. Such an integrated approach still creates some additional costs for project planning, excavation, shutting off traffic and extraction and transportation of cables to metal recyclers. The magnitude of additional costs for cable recovery during maintenance works was collected from SwedEnergy (2009).

The revenues that managers of the grid obtain for extracted cables largely follow the international market price for copper (5.45€ per $\mathrm{kg}$ on 6/17/2010). However, metal recyclers also charge a fee of $0.3 €$ per $\mathrm{kg}$ of cable for processing and recycling expenditures (Lind, 2010, Stena Recycling $\mathrm{AB}$, personal communication). When calculating the economic performance, the revenues for different cables, containing different amounts of copper per metre, were then related to the costs for extraction.

\section{Stocks of copper in the power grids of Gothenburg and Linköping, Sweden}

\subsection{In-use copper stocks}

In the city of Gothenburg, the total accumulation of copper in the operational power grid is approximately 9,500 tonnes, which is almost twice as much copper as in the present cable network in Linköping, Figure 2. However, on a per customer basis, the two grids contain similar amounts of copper; in Gothenburg 0.04 tonnes per subscriber and in Linköping 0.05 tonnes per subscriber. These in-use stocks of copper primarily consist of cables with copper as the main conductor while aluminium conductors, only containing copper in the cable shield, contribute less than $10 \%$ to the copper stocks in the grids.

Although the size of the power grids in the two cities obviously is different, their general structure displays similarities. For instance, the main part of the grids is buried in the ground although a slightly larger share of the power cables is airborne in Linköping. It is also the case that in both cities the in-use copper stock is fairly evenly distributed between medium- $(6-24 \mathrm{kV})$ and low-voltage cables $(<1 \mathrm{kV})$, despite the fact that the low-voltage networks are almost twice as long as the medium-voltage grids in the cities. Compensating for the shorter length of the medium-voltage networks is the fact that such cables generally contain significantly more copper per metre. 


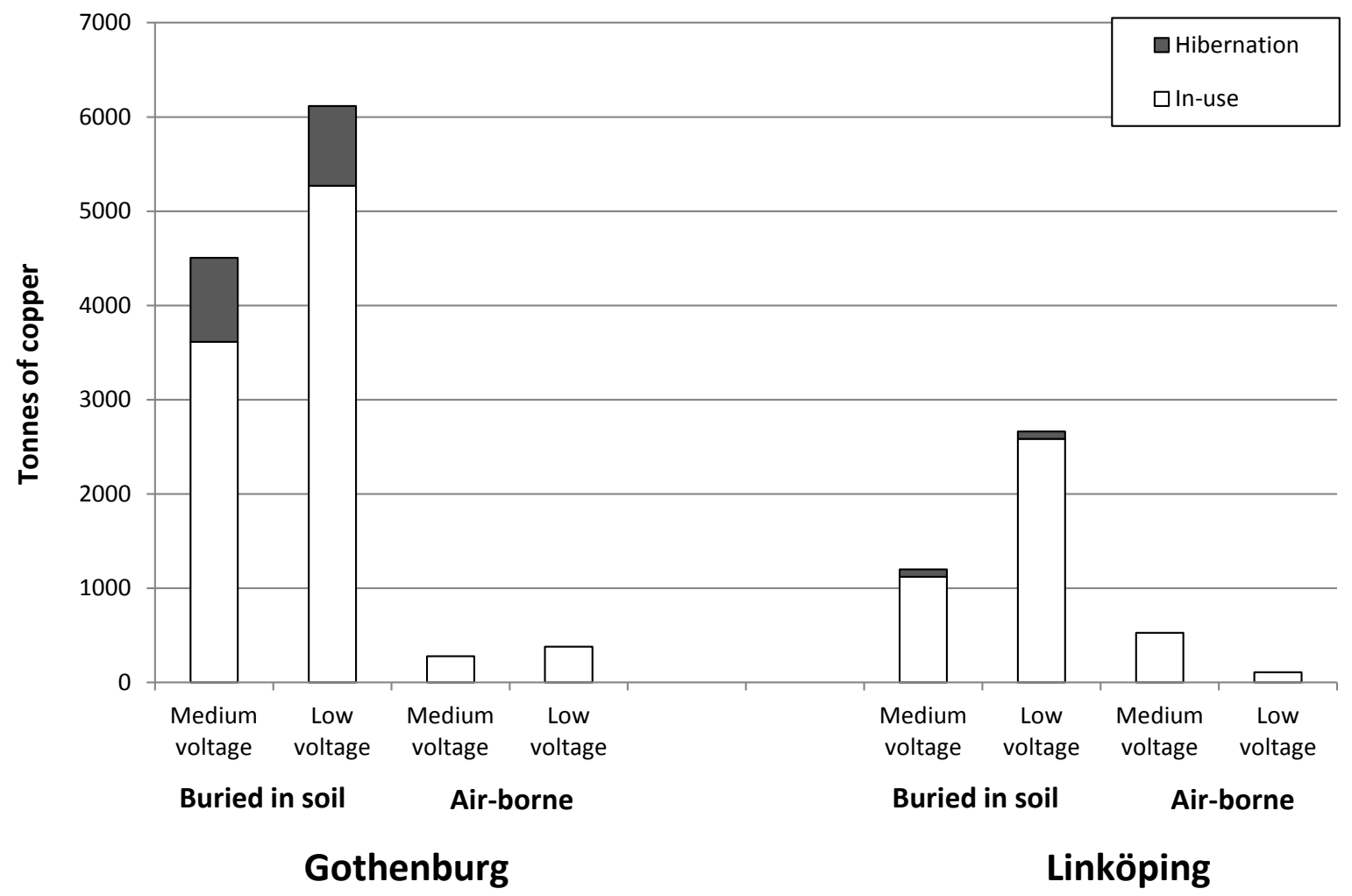

Figure 2. In-use and hibernating stocks of copper (tonnes) accumulated in the city power grids of Gothenburg and Linköping, distributed on cables buried in soil and airborne cables.

\subsection{Hibernating copper stocks in the power grids}

Apart from in-use copper stocks, the results from this study show that the power grids in Gothenburg and Linköping also contain significant amounts of copper in hibernation, Figure 2. Such obsolete copper stocks reside in parts of the power grids that over time have been disconnected without being collected for waste management. Virtually all of these disconnected cables are situated underground since such cables are, in contrast to airborne networks, often left as is when taken out of use. In both cities, approximately half of the hibernating copper is located in low-voltage cables while the other half is found in obsolete medium-voltage grids.

In the city of Gothenburg, the total amount of copper accumulated in the obsolete parts of the power grid is approximately 1,700 tonnes, displaying a ratio of in-use copper to hibernating copper of close to 6:1. In the city of Linköping, in which only a small part of the cable network is disconnected, the power grid contains slightly more than 150 tonnes of hibernating copper. The ratio of in-use copper to hibernating copper is therefore substantially different, i.e. $28: 1$. 


\section{Conditions for extracting hibernating power cables in the city of Linköping}

Why do cables end up in hibernation in the first place? According to the manager of the power grid in Linköping, cables most often end up in hibernation when they are replaced by new cables. There could be several reasons for such substitution, such as when the capacity for parts of the grid is too low to meet increasing needs for higher voltage levels or environmental reasons, e.g. substitution of copper cables for cables with aluminium conductors. A typical case however is when an old but still operational cable is to be replaced. In order to secure a continuous power supply during such projects, the old cable must be kept in operation until the entire new cable has been put in place and connected to the grid. Due to high costs for having open shafts in the city environment, such maintenance work is always done in stages where a part of the grid, approximately 100 metres, is excavated, maintained and re-buried at one time. So, when the project is completed and it is finally time to disconnect the old cable, the main part of the grid has already been re-buried, making it impossible to extract this cable, at least by conventional technologies.

In the city of Linköping, initiatives solely for extracting hibernating cables are at present not considered conceivable for economic reasons, especially since such obsolete grids often are situated under footpaths and pavements. In such an environment, revenues for recovered cables do not in fact come even close to outweighing costs for excavation and site restoration (including asphalting), storage of excavated soil, land rental from the municipality, shutting off traffic and handling of cables, Table 3. For a low-voltage service cable, containing about $0.8 \mathrm{~kg}$ of copper per metre, the revenue is at present $4 €$ per metre while medium-voltage cables or low-voltage feeder cables generate an income of $16 €$ per metre since they are more rich in copper (i.e. typically contain $3 \mathrm{~kg}$ of copper per metre). The total project cost for extracting hibernating cables in the city is however about $112 €$ per metre of excavated shaft. So, for medium- or lowvoltage feeder cables, the present copper price (i.e. $5.4 €$ per $\mathrm{kg}$ of copper) would have to increase by at least a factor of 7 to make such initiatives an economic option for owners of power grids. For low-voltage service cables, a 25 -fold increase in the copper price would be necessary.

A more viable approach could be to extract hibernating cables at the same time as other maintenance work is being done on the grid in the city. This is possible since virtually all of the obsolete cables in Linköping are co-located in the same shafts as the grids in operation. Although the ordinary project costs for maintenance remain the same, and could thus not be allocated to extracting cables from the shaft, such an integrated approach does create some additional expenses (e.g. supplementary time for project planning, excavation, shutting off traffic and extraction and transportation of cables to metal recycling companies). The magnitude of such extra costs for cable recovery is heavily reliant on case-specific conditions, e.g. exactly where in the city the excavation takes place, and could vary from 5 to $21 €$ per metre of cable. For cables containing about $3 \mathrm{~kg}$ of copper per metre, however, the results from this study show that the present revenues (i.e. $16 €$ per metre) could in many cases exceed such additional project costs. 
In the city of Linköping, awareness of possibilities of combining ordinary maintenance work on the power grid with recovery of hibernating cables has gradually increased. According to the power grid manager, however, this opportunity is so far seldom realised. It is important to understand that for managers of power grids this is still a new phenomenon largely peripheral to their core business, which is distribution of electricity to final users. In Linköping, there is an "unspoken" policy to take care of hibernating cables. However, this "will" has not yet been incorporated into the traditional procedures for project planning. This, in fact, reveals an important organisational obstacle for recovery of obsolete cables since the hired contractors, who do the actual maintenance work on the grid, will not take initiatives of their own beyond the stated project plan.

Table 3. Economic performance, in Euros $(€)$ per meter of excavated shaft, for extraction of hibernating power cables in the city environment by two different approaches; separate recovery of obsolete cables and integrated recovery during other maintenance work on the grid.

\begin{tabular}{|c|c|c|c|c|c|}
\hline \multirow[t]{2}{*}{ Approach } & \multicolumn{2}{|c|}{ Revenue $(€)$} & \multirow[t]{2}{*}{ Project cost $(€)$} & \multicolumn{2}{|c|}{ Economic performance $(€)$} \\
\hline & $\begin{array}{l}\text { Low-voltage } \\
\text { service cable }\end{array}$ & $\begin{array}{c}\text { Medium-voltage } \\
\text { cable }\end{array}$ & & $\begin{array}{l}\text { Low-voltage } \\
\text { service cable }\end{array}$ & $\begin{array}{c}\text { Medium-voltage } \\
\text { cable }\end{array}$ \\
\hline $\begin{array}{l}\text { Separate cable } \\
\text { recovery }^{\mathrm{a}}\end{array}$ & 4 & 16 & 112 & -108 & -96 \\
\hline $\begin{array}{l}\text { Integrated cable } \\
\text { recovery }\end{array}$ & 4 & 16 & $5-21$ & $-17--1$ & $-5-11$ \\
\hline
\end{tabular}

${ }^{a}$ The project cost for excavation, extraction and handling of obsolete copper cables has been calculated at $112 €$ per metre and is here fixed while the revenue for the recovered cable is allowed to vary between $4 €$ and $16 €$ dependent on the copper content $(0.83 \mathrm{~kg}$ copper per metre for a low-voltage service cable and $3.3 \mathrm{~kg}$ copper per metre for a medium-voltage cable or a low-voltage feeder cable).

${ }^{\mathrm{b}}$ The additional costs for integrated extraction of hibernating power cables as other maintenance work is performed range from $5 €$ to $21 €$ per metre. As for separate cable recovery, the revenue for the recovered cable is also here allowed to vary between $4 €$ and $16 €$ per metre, see above.

\section{Concluding discussion}

This study demonstrates large differences in occurrence of hibernating copper in local power grids. In Gothenburg, the share of copper in the grid that is no longer in use is almost 20\%, while this obsolete share of the accumulated stock does not exceed 5\% in the city of Linköping. For electr(on)ic equipment in private residences in the state of Connecticut (USA), Kapur and Graedel (2006) report that the share of copper in hibernation is close to $8 \%$. For such products, e.g. refrigerators, televisions and desktop computers, this phenomenon might only result in delaying the outflow to waste management and recycling. In large technical systems of the type addressed in this study, resource implications of hibernation could however be much more 
severe. This is because there is an overwhelming risk that such urban stocks of strategically important metals become permanently forgotten, especially if they are situated below ground. Research on why hibernation occurs is therefore essential in order to better understand how to prevent materials from ending up in such an unfavourable state.

Although this study strictly focuses on copper in local power grids, it still represents one of only a few studies in which hibernating material stocks in the built environment have been quantified. Such knowledge about occurrence of obsolete urban stocks illuminates already accessible alternative sources for resource extraction - reservoirs that are likely to become increasingly important to exploit. The results from this study indicate that the amount of hibernating materials in large technical systems could be substantial. In the two studied city power grids, involving $10,000 \mathrm{~km}$ of power cables, about 1,850 tonnes of obsolete copper is currently situated. Assuming that the concentration of hibernating copper in such cable networks generally is approximately 0.2 tonnes per $\mathrm{km}$, local power grids would for Sweden as a whole (in total $490,000 \mathrm{~km}$ according to Energy Market Inspectorate, 2010) contain close to 90,000 tonnes of obsolete copper. In a Swedish context, such a reservoir of copper resource is significant, corresponding to $60 \%$ of the annual consumption of this metal in the country (cf. SEPA, 1996).

There are however several other large technical systems, apart from city power grids, that are rich in valuable metals and thus could constitute potential urban sources for resource extraction (cf. Gerst and Graedel, 2008). For instance, the Swedish communication network involves approximately 1,000,000 km of cables (SKANOVA, 2010), most of which are buried in soil. Such communication cables generally contain much more copper than power cables, especially regional networks where the concentration of copper varies between 10 and $20 \mathrm{~kg}$ per metre of cable (Wendell, 2005). Assessing the occurrence of hibernating metal stocks in water and gas supply systems, old industrial areas and decommissioned military structures could comprise other research topics for dimensioning the overall potential of urban mining.

Despite the magnitude of copper in hibernation and hence the theoretical potential of urban mining of metals in power cables no longer in use, the conditions for recovery are in many cases not yet favourable for this action. As illustrated by the economic analysis of urban mining performed in this study, it is not likely that separate cable recovery will be economically justified in a city environment. However, in light of today's copper prices, extracting hibernating cables at the same time as other maintenance work is done on the grid could be beneficial from an economic point of view. This operation requires knowledge however about the share of cables in hibernation as well as their exact location. For the local power grid covered in this paper, it was shown that almost all cables in hibernation were co-located in the same shaft as the grid in operation - a parameter that thus would facilitate urban mining initiatives. In other cases, the availability of integrated recovery of cables would likely also require collaboration with other actors that have interest in the same shaft as the hibernating power cables of interest, e.g. 
managers of communication networks. Other potential parameters for facilitating urban mining of cables could be technology development making it possible to extract cables in hibernation without extensive activities such as opening the shaft, or requirements by landowners where cables are located that no cables are left behind after being taken out of use. Analysing such technical, economic and institutional conditions for realisation is perhaps one of the most important future research tasks for stimulating urban mining initiatives.

\section{Acknowledgements}

Financial support from the Swedish Innovation Agency, VINNOVA, is gratefully acknowledged.

\section{References}

Anderberg, S., and Stigliani, W. M., 1994. An integrated approach for identifying sources of pollution: The example of cadmium pollution in the Rhine River basin. Water Science \& Technology, 29, 61-67.

Bergbäck, B., Johansson, K. and Mohlander, U., 2001. Urban metal flows - A case study of Stockholm. Water, Air and Soil Pollution. 1, 3-24.

Brunner, P.H. and Rechberger, H., 2004. Practical Handbook of Material Flow Analysis, Boca Raton: Lewis Publishers.

Energy Market Inspectorate, 2010. http:// www.energimyndigheten.se/ [accessed 8/6/2010]

Gerst, M.D. and Graedel, T.E., 2008. In-use stocks of metals: Status and implicaitions. Environmental Science \& Technology, 42, 7038 - 7045.

Gordon, R.B., Bertram, M., and Graedel, T.E., 2006. Metal stocks and sustainability. PNAS, 103 (5), 1209-1214.

Hedbrant, J., 2003. Structuring Empirical Knowledge on Environmental Issues. Urban Heavy Metal Metabolism. PhD thesis. Linköping Studies in Arts and Science 283, Linköping, Sweden.

Kapur, A., 2006. The future of the red metal: discards, energy, water, residues and depletion. Progress of Industrial Ecology - An International Journal, 3, 209-236.

Kapur, A., and Graedel, T.E., 2006. Copper mines above and below ground. Estimating the stocks of materials in ore, products, and disposal sites opens up new ways to recycle and reuse valuable resources. Environmental Science \& Technology, 40, 3135-3141.

Lifset, R.J., Gordon, R.B., Graedel, T.E., Spatari, S. and Bertram, M., 2002. Where has all the copper gone. JOM, 54, 21-26.

Lindqvist, A. and von Malmborg, F., 2004. What can we learn from local substance flow analyses? The review of cadmium flows in Swedish municipalities. Journal of Cleaner Production, 12, 909-918.

Müller, D., Wang, T., Duval, B., and Graedel, T.E., 2006. Exploring the engine of anthropogenic iron cycles. PNAS, 103, 16111-16116.

Recalde, K., Wang, J. and Graedel, T.E., 2008. Aluminum in-use stocks in the state of Connecticut. Resources, Conservation and Recycling, 52, 1271-1282. 
SEPA, 1996. Metaller - materialflöden i samhället/Metals - Material flows in society. The Swedish Environmental Protection Agency, Report 4506, Stockholm (in Swedish).

SKANOVA, 2010. http://www.skanova.se/ [accessed 11/8/2010] (in Swedish)

SwedEnergy, 2009. Hantering av uttjänt kabel/Management of worn-out cables. HMS 04:09. http://www.svenskenergi.se/ [accessed 8/6/2010] (in Swedish)

UNEP, 2010. Metal stocks in society. Scientific Synthesis Global Metals Flows Group of UNEP's International Panel for Sustainable Resource Management. Available at: http://www.unep.org/metalstocks/documents/pdf/MetalStocksInSocietyScienceSynth_full_en. pdf [accessed $14 / 6 / 2010]$.

Van Beers, D. and Graedel, T.E., 2003. The magnitude and spatial distribution of in-use copper stocks in Cape Town, South Africa. South African Journal of Science, 99, 61-69.

Van der Voet, E., Guinée J. B. and Udo de Haes, H. A., 2000. Heavy Metals: A Problem Solved? Methods and Models to Evaluate Policy Strategies for Heavy Metals. Dordrecht: Kluwer Academic Publishers.

Wendell, J., 2005. Cables-Societal Stock and Potential for Increased Recycling. Master Thesis, Linköping University, LITH-IKP-EX-05/2252-SE.

Wittmer, D. and Lichtensteiger, T., 2007. Development of anthropogenic raw material stocks: a retrospective approach for prospective scenarios. Minerals \& Energy 22, 62-71. 